\title{
Commentary: Straight into the heart of danger: Central aortic cannulation for aortic dissection
}

\author{
Ayman Almousa, MD, and Ravi K. Ghanta, MD
}

\footnotetext{
From the Division of Cardiothoracic Surgery, Michael E. DeBakey Department of Surgery, Baylor College of Medicine, Houston, Tex.

Disclosures: Authors have nothing to disclose with regard to commercial support.

Received for publication Dec 16, 2018; accepted for publication Dec 17, 2018; available ahead of print Jan 17 , 2019.

Address for reprints: Ravi K. Ghanta, MD, Division of Cardiothoracic Surgery, Michael E. DeBakey Department of Surgery, One Baylor Plaza, MS 390, Houston, TX 77030-3411 (E-mail: Ravi.ghanta@bcm.edu).

J Thorac Cardiovasc Surg 2019;158:37-8

$0022-5223 / \$ 36.00$

Copyright (C) 2018 by The American Association for Thoracic Surgery

https://doi.org/10.1016/j.jtcvs.2018.12.052
}

Type A aortic dissection (TAAD) requires expedient surgical treatment. The first challenge encountered by cardiac surgeons is cannulation strategy for cardiopulmonary bypass. Cannulation requires thoughtful integration of the aortic anatomy, dissection extent, planned aortic repair strategy, prior surgical history, and hemodynamic status. Femoral cannulation has been a traditional mainstay in dissection repair. As techniques for cerebral perfusion have evolved, proximal arterial cannulation has increased to allow for antegrade flow and antegrade cerebral perfusion. ${ }^{1}$ However, the decision to implement arterial cannulation becomes more challenging in unstable patients and those experiencing shock. Peripheral cannulation requires time, which may be precarious in some patients.

Kreibich and colleagues ${ }^{2}$ from the University of Pennsylvania demonstrate the safety of central ascending aortic cannulation in acute TAAD in a large cohort of patients. Although this group and others have previously described this technique, ${ }^{3}$ the current study has several important findings. First, this experience in a large cohort of 355 central aortic cannulation patients demonstrates the safety of this strategy. In the authors' experience, they encountered no failed cannulations or iatrogenic aortic rupture. In addition, central aortic cannulation was associated with decreased operative time compared with axillary cannulation and equivalent to femoral cannulation. Few centers routinely use central aortic cannulation for TAAD, likely due to unfamiliarity with the technique. Experience may be obtained with Seldinger technique aortic cannulation during routine cases and routine transesophageal echocardiographic identification of the true and false lumen in TAAD. When we utilize central aortic cannulation, we avoid areas of hematoma and are cognizant of intimal tear locations identified on computed tomography scanning. Second, the authors demonstrate that antegrade cerebral perfusion is still possible with central cannulation utilizing balloon-tipped cannulas placed in the innominate as well. dissection.

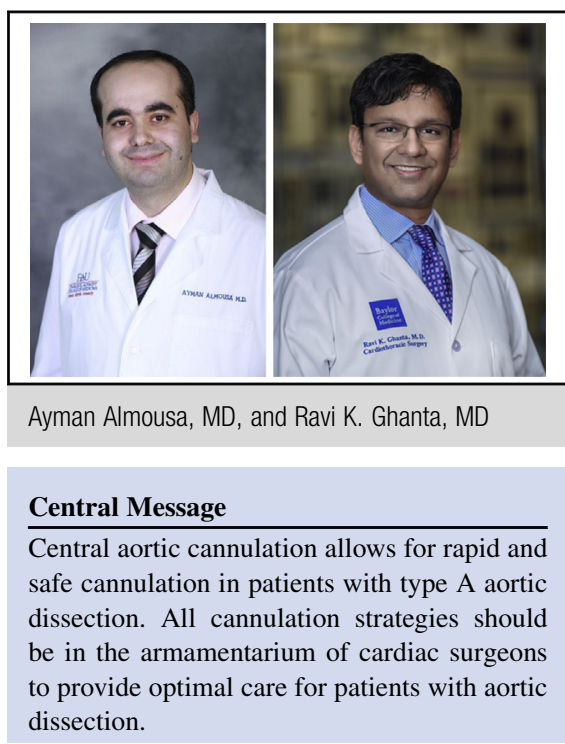

See Article page 27.

and/or left carotid artery ostia. Central aortic cannulation was more frequently associated with retrograde cerebral perfusion (74\%) compared with axillary cannulation $(29 \%)$. Although retrograde cerebral perfusion is a widely utilized option, we prefer antegrade cerebral perfusion whenever possible. Consequently, the innominate artery is our primary option for cannulation in TAAD, which can be performed rapidly in nonreoperative patients. ${ }^{4}$ Third, the authors demonstrate that axillary cannulation is safe even when the innominate artery is involved in the dissection. In this study, among 208 patients with innominate artery dissection, 40 underwent axillary cannulation. The final important point of this study is that femoral cannulation demonstrated a trend $(P=.051)$ toward greater incidence of neurologic deficit. This is consistent with other data demonstrating potential concerns of retrograde arterial flow in non-TAAD pathology

The authors are to be congratulated for a clinically relevant analysis of a large cohort of patients with TAAD. Sometimes, to follow the old proverb, safety is found in the heart of danger and central aortic cannulation of a dissected aorta represents the best option. All cannulation strategies need to be in the armamentarium of cardiac surgeons who care for patients with aortic 


\section{References}

1. Hawkins RB, Mehaffey JH, Downs EA, Johnston LE, Yarboro LT, Fonner CE, et al. Regional practice patterns and outcomes of surgery for acute type A aortic dissection. Ann Thorac Surg. 2017;104:1275-81.

2. Kreibich M, Rylski B, Bavaria JE, Brown CR, Branchett E, Vallabhajosyula P, et al. Outcomes after aortic, axillary, or femoral cannulation for acute type A aortic dissection. J Thorac Cardiovasc Surg. 2019;158:27-34.
3. Reece TB, Tribble CG, Smith RL, Singh RR, Stiles BM, Peeler BB, et al. Central cannulation is safe in acute aortic dissection repair. $J$ Thorac Cardiovasc Surg. 2007; 133:428-34.

4. Preventza O, Bakaeen FG, Stephens EH, Trocciola SM, de la Cruz KI, Coselli JS Innominate artery cannulation: an alternative to femoral or axillary cannulation for arterial inflow in proximal aortic surgery. J Thorac Cardiovasc Surg. 2013;145: S191-6. 